\title{
Seeing COVID-19 through an urban lens
}

\author{
Michele Acuto, Shaun Larcom, Roger Keil, Mehrnaz Ghojeh, Tom Lindsay, \\ Chiara Camponeschi and Susan Parnell
}

Pandemic responses can engender healthier and more sustainable societies only if we attend to urban equality.

C OVID-19 has changed the face of cities and recast urban life globally.

In turn, cities have become the major theatres of the crisis for a once-in-a-century test to global resilience. Global health governance has thus far struggled to face up to the urban character of the pandemic. The United Nations (UN) Secretary General recently called for a better appreciation of how COVID-19 is unfolding in 'an urban world' if we are to rebuild more sustainably ${ }^{1}$. We argue it is imperative to do so by attending to urban inequalities that underpin the crisis, and by understanding the fundamental inclusive development opportunity at play here if we allow urban expertise, and cities, closer to the heart of the global response.

Under the presumptive 'new normal' of COVID-19, multiple intersecting policy agendas have come to the fore not just in the shape of health concerns but also with regards to environmental sustainability and 'green' economic recovery. Much of this has had to do with recasting the ways we live in cities. The UN has already stressed that approximately $95 \%$ of COVID-19 cases have taken place in urban settlements, with over 1,500 cities affected worldwide ${ }^{2}$. Many have made the case that post-pandemic planning discussion must transcend dualistic framings pitting 'health' versus 'environmental' concerns ${ }^{3}$, whilst not giving in to simplistic economic growth approaches ${ }^{4}$. By far and large that implies radical changes to our cities and urban livelihoods. Yet these are rarely at the centre of the multilateral debate. We urgently need to attend to the urban socio-economic crisis underpinning COVID-19 that unfolds amidst the most vulnerable in cities both at the inter- and intra-urban scale.

The World Bank now warns of a wave of 49 million COVID-19-driven 'new urban poor', affecting millions of rural-urban migrants and adding to concerns about the more than one billion people living in informal urban settlements. Seeing the crisis through an urban lens implies starting from the fundamental inequalities that underpin our urban world across the various global policy agendas currently battling for attention. It means viewing global health governance from the realities of urban collective life up ${ }^{6}$. It implies not equating cities with local governments and localized issues only, but seeing cities as turnstiles in global challenges and key contexts for multi-level governance. It stresses the importance of city networks not just of people, viruses and goods, but also of solidarity, policymaking, knowledge and dependency ${ }^{7}$. The pandemic spread fast across the world and continues to circulate because of the global system of human settlements. It now reaches deep into rural and peri-urban realities and feeds on national and international connections that go beyond the links between major global cities - with planetary ramifications ${ }^{8}$. In turn, in spite of little global governance recognition, COVID-19 has sprung, or perhaps forced, many cities to act, making municipal authorities the frontlines of global health governance 9 . Yet this has not reinforced their legitimacy as actors on an international or national stage or the voice of urban experts in global debates. With rates of urbanization predicting an increase of the world's urban population to six billion by 2045 , this is not just an immediate urban challenge but a long-term global concern. The urgency to 'see like a city' is clear.

\section{Box 1 | Mobility and the post-COVID-19 city}

Some of the most incisive shifts at the heart of COVID-19 lockdowns and contagions relate to the ways people move in and between urban settlements. The transformation of mobility has been dramatic. Seeing recovery efforts 'like a city' could achieve a fundamental restructuring of the world's urban economies in relation to commuting and transportation. These are an intersectional terrain where climate emergency politics, infrastructure investment and health meet and where meaningful joint action can be initiated immediately. The chance at hand is sizeable. Interventions in this area could decouple economic development from air pollution, in turn leading to tangible physical and mental health benefits ${ }^{16}$.

Widening automobile restrictions can be a positive outcome of the lockdowns when implemented in tandem with the expansion of public transportation and active mobility networks. However, the success of any such innovations needs to be measured against their accessibility and affordability by the most marginalized urban areas. These are often inner suburban neighbourhoods where poverty, racialized and gendered segregation are dominant. For cities in developing countries, the challenges of post-COVID-19 mobility must also take on the deep structural issues of inadequate infrastructure and weak planning systems that have long precluded investments for the public good.

Seeing this challenge like a city is also about appreciating its mundanity. In the redesign of everyday urban life, a sizeable revolution could ensue. Much can be learnt from the small and habitual. Urban economics already tells us that when commuters are faced with even relatively minor disruptions, temporary shifts in behaviours can lead to lasting changes ${ }^{17}$. Many cities have already understood how this can be done affordably and sustainably. Yet the imperative to get urban dwellers moving is urgent. In developing contexts all but $15 \%$ of the population are able to work from home with most urban livelihoods fundamentally threatened. With an urban logic in mind, COVID-19 interventions must be general in nature but specific in application, attending to the diversity of billions of urban dwellers affected by the crisis. This is a lesson in inclusive recovery that is transferrable to other similar domains of action like housing, services and governance. 


\section{Seeing COVID-19 like a city}

Re-building cities post-COVID-19 requires negotiating multiple, concurrent needs in order to meaningfully address the complexity of how contagion, sustainability and economic recovery work in urban settlements. Understanding this crisis from the point of view of urban research and action, or as Warren Magnusson put it, 'seeing like a city', means stepping beyond the confines of state-centric views to embrace the political-economic complexity of the 'urban'10. It means appreciating how a multiplicity of powers and interests shape our urban lives through different registers ranging from the municipal, to communities and urbanized private sector, each checking, regulating or challenging the others. It calls for an acceptance of the valuable diversity of urban (research and theory) points of view and the productive result of their conversation $^{11}$.

This urban lens on COVID-19 offers at least four advantages. First, it recognizes the global role of 'extended urbanization' and its interplay with planetary health ${ }^{12}$. The stretching of our urbanized life across shared ecologies is at the basis of both our changing climate and the acceleration of zoonotic events like COVID-19, whilst exacerbating urban divides between the core and periphery of our globally linked cities. Second, it values learnings that emerge from moments of crisis and lessons that surface from mundane innovations in the midst of disruptions. COVID-19 lockdowns are a unique 'forced experimentation' we cannot underestimate ${ }^{13}$. An urban lens can allow us to leverage this moment for more inclusive and sustainable service delivery in cities (see Box 1 for an example). Yet reconfiguring urban spaces in a time of crisis must also include exposing facile 'urbanist' agendas that reinforce gentrification and the expulsion of migrant residents.

Third, it values the active role played by citizens and urban communities in crisis response, often in collaboration with powerful philanthropic and private sector actors. Community-based initiatives cannot and should not replace the welfare obligations of the state but tend to be more attuned to the needs and the demands of the most vulnerable ${ }^{14}$.

Fourth, it reminds us that cities are not just local governments but also their residents. The surge of community solidarity and mutual aid funds that has accompanied the spread of the virus asks us to appreciate the value of local interventions and underscores the potential to reconstitute urban lives and relationships according to new more inclusive scripts. When seen through an urban lens, these examples demonstrate that social justice, public health and environmental agendas are mutually reinforcing parts of an integrative whole and attention to livelihoods is as critical as that to health.

\section{A window of urban opportunity}

An urban lens on the COVID-19 crisis underscores the window of opportunity we have to inform recovery plans before they are locked-in unsustainably. The need for international actors and central governments to better 'see like cities' is a real and pressing one. The Organisation for Economic Co-operation and Development expects local authorities to generate up to $25 \%$ less revenues next year, making it difficult to maintain current levels of service delivery, let alone invest in inclusive and sustainable development ${ }^{15}$. Outside of the initiative by city networks, cities are still very much on the sidelines of multilateralism. The World Health Organization, for instance, still does not have a major 'cities' unit and has often sidelined urban health in favour of state-centric conversations. At the same time, urban research still does not have the same global purchase of, for example, climate science when it comes to presenting a clear collective voice on the international stage. We call for the inclusion of cities and urban expertise at the heart of pandemic response, with presence and consultation at the multilateral table, as well as for their explicit involvement in the planning of post-COVID-19 recovery by states, multilateral organizations and the private sector.

Michele Acuto (D1ه, Shaun Larcom (iD), RogerKeil (iD ${ }^{3}$, MehrnazGhojeh $^{4}$, TomLindsay $^{5}$, ChiaraCamponeschi (D) ${ }^{6}$ and SusanParnell (D) 7,8

${ }^{1}$ University of Melbourne, Melbourne, Victoria, Australia. ${ }^{2}$ University of Cambridge, Cambridge, UK. ${ }^{3}$ York University, Toronto, Ontario, Canada. ${ }^{4} \mathrm{C} 40$ Climate Leadership Group, London, UK. ${ }^{5}$ Coalition for Urban Transitions, London, UK. ${ }^{6}$ Enabling City, Toronto, Ontario, Canada. ${ }^{7}$ University of Bristol, Bristol, UK. ${ }^{8}$ University of Cape Town, Cape Town, South Africa.

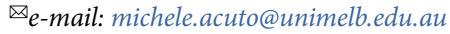

Published online: 16 September 2020

https://doi.org/10.1038/s41893-020-00620-3

References

1. Policy Brief: COVID-19 in an Urban World (United Nations, 2020); https://go.nature.com/335VRRS

2. Bhalla, N. Coronavirus will travel 'incredibly fast' in Africa's slums, U.N. cities chief warns. Reuters (24 April 2020); https://go.nature.com/338tuCj

3. Engström, G. et al. Environ. Resour. Econ. 76, 789-810 (2020).

4. Guerriero, C., Haines, A. \& Pagano, M. Nat. Sustain. 3, 494-496 (2020).

5. Wilkinson, A. et al. Environ. Urban. https://doi.org/10.1177\% 2F0956247820922843 (2020).

6. Bhan, G., Caldeira, T., Gillespie, K. \& Simone, A. The pandemic, southern urbanisms and collective life. Society and Space (3 August 2020); https://go.nature.com/2FligGL

7. Bai, X., Nagendra, H., Shi, P. \& Liu, H. Nature 584, 517-520 (2020).

8. Brenner, N. Public Cult. 25, 85-114 (2013).

9. Dodds, K. et al. Territ. Polit. Gov. 8, 289-298 (2020).

10. Magnusson, W. Politics of Urbanism: Seeing Like a City (Routledge, 2013).

11. Acuto, M., Parnell, S. \& Seto, K. C. Nat. Sustain. 1, 2-4 (2018).

12. Connolly, C., Keil, R., \& Ali, S. H. Urban Stud. https://doi.org/10.1 177\%2F0042098020910873 (2020).

13. Acuto, M. One Earth 2, 317-319 (2020)

14. Fallah, M. et al. Ann. Intern. Med. 164, 367-369 (2016).

15. City policy responses. OECD (23 July 2020); https://go.nature. $\mathrm{com} / 3 \mathrm{~m} 12 \mathrm{RI} 6$

16. Li, X., Jin, L. \& Kan, H. Nature 570, 437-439 (2019).

17. Larcom, S., Rauch, F. \& Willems, T. Q. J. Econ. 132, 2019-2055 (2017).

Competing interests

The authors declare no competing interests. 